\title{
Sonodynamic therapy induces apoptosis of human leukemia HL-60 cells in the presence of protoporphyrin IX
}

\author{
Xiaomin $\mathrm{Su}^{1,3}$, Xiaobing Wang ${ }^{1}$, Kun Zhang ${ }^{1}$, Shuang Yang ${ }^{1}$, Quanhong Liu ${ }^{1}$, Albert W. Leung ${ }^{2}$, \\ Chuanshan $\mathrm{Xu}^{2}$ and Pan Wang ${ }^{1,2}$ \\ ${ }^{1}$ Key Laboratory of Medicinal Resources and Natural Pharmaceutical Chemistry, Ministry of Education, National Engineer- \\ ing Laboratory for Resource Developing of Endangered Chinese Crude Drugs in Northwest of China, College of Life Sciences, \\ Shaanxi Normal University, Xian, Shaanxi, China \\ ${ }^{2}$ School of Chinese Medicine, Faculty of Medicine, The Chinese University of Hong Kong, Shatin, Hong Kong, China \\ ${ }^{3}$ The Blood Center of Xi'an, Xian, Shaanxi, China
}

\begin{abstract}
Sonodynamic therapy (SDT) is expected to be a novel therapeutic strategy for tumor. The protoporphyrin IX disodium salt (PpIX), a photosensitizer, can be activated by ultrasound. The present study aims to investigate apoptosis of HL-60 cells induced by PpIX-mediated SDT. 3-(4, 5-dimethylthiazol-2-yl)-2,5-diphenyl tetrazolium bromide (MTT) assay was adopted to examine cell toxicity. Apoptosis was detected using Annexin V-PE/7-amino-actinomycin D (7-AAD) double staining. Detection of apoptotic bodies was examined by Hoechst33342 (HO) staining. Western blotting was used to analyze the protein of caspase- 3 and poly ADP-ribose polymerase (PARP). Intracellular reactive oxygen species (ROS) was detected by a flow cytometer after exposures. Compared with PpIX alone and ultrasound alone groups, the synergistic cytotoxicity of PpIX plus ultrasound were significantly boosted. In addition, as determined by Annexin V-PE/7-AAD staining, SDT significantly induced HL-60 cell apoptosis, the obvious nuclear condensation was also found with HO staining at 4 hours post-SDT treatment. Furthermore, Western blotting showed visible enhancement of caspase-3 and PARP cleavage in this process. Besides, intracellular ROS production was significantly enhanced after SDT. Our findings demonstrate that PpIX-mediated SDT could induce apoptosis on HL-60 cells, suggesting that apoptosis is an important mechanism of cell death induced by PpIX-mediated SDT.
\end{abstract}

Key words: Sonodynamic therapy - PpIX - Leukemia HL-60 cells - Apoptosis

\section{Introduction}

Leukemia is a disease manifested by the failure of cell death, or inability of hematopoietic cells to differentiate into functional mature cells (Koeffler 1983; Collins 1987). Presently, the traditional cancer therapies for leukemia treatment, including chemotherapy and bone marrow transplantation,

Correspondence to: Pan Wang, School of Chinese Medicine, Faculty of Medicine, The Chinese University of Hong Kong, Shatin, Hong Kong, China

E-mail: wangpan@snnu.edu.cn

Chuanshan Xu, School of Chinese Medicine, Faculty of Medicine, The Chinese University of Hong Kong, Shatin, Hong Kong, China

E-mail: xcshan@163.com show some limitations because of drug resistance, poor prognosis and serious side effects, etc. Therefore, novel therapeutic strategies, preferably consisting of noninvasive treatments, are urgently required.

Sonodynamic therapy (SDT), a novel strategy in tumor treatment, shows synergistic effects on cell killing by the combination of a sonosensitizer and ultrasound, which are based on photodynamic therapy (Liu et al. 2006, 2008). Many recent reports concerning SDT have focused on apoptotic events after ultrasound irradiation with a photosensitizer in vitro (Wang et al. 2008; Tang et al. 2010). Lagueaux et al. found that ultrasound exposure can induce apoptotic response in human leukemia cells such as HL-60, Kgla, and Nalm-60 (Lagneaux et al. 2002). Yumita et al. observed sonodynamically induced apoptosis in HL-60 cells (Yumita et al. 2010). In conclusion, this method of treating diseases 
induced by ultrasound may have future clinical applications (Amir et al. 2010).

SDT uses ultrasound to activate a sonosensitizer, which selectively accumulates in cancer cells or tissues. Protoporphyrin IX (PpIX) is an efficient hydrophobic sensitizer which is activated by both light and ultrasound waves (Liu et al. 2007). In our past study, we used low-intensity ultrasound to activate PpIX and our data showed that sonodynamic action of PpIX significantly enhanced the cell apoptosis (Wang et al. 2010). Further, it was found that certain drugs, upon ultrasonic irradiation, created active oxygen species such as superoxide radicals and singlet oxygen, and that the active oxygen thus destroyed cancer cells effectively (Miyoshi et al. 1997). More recently, Song, et al. reported that the reactive oxygen species (ROS) may play an important role in ultrasonically-induced cell apoptosis with the presence of 5-aminolevulinic acid, and sonosensitizer activation generates ROS that destroyed the cell membrane and intracellular substances (protein and nucleic acid) to promote apoptosis (Song et al. 2011).

Therefore we are interested in assessing its safety through exploration of its biological effects. In the present study, we have focused on investigating the apoptosis of HL-60 cells induced by PpIX-mediated sonodynamic action in vitro.

\section{Materials and Methods}

\section{Chemicals}

Protoporphyrin IX disodium salt (PpIX) was purchased from Sigma Chemical Company (St Louis, MO, USA) and was dissolved in RPMI-1640 medium ( $\mathrm{pH} \mathrm{7.2)} \mathrm{at} 2 \mathrm{mg} /$ $\mathrm{ml}$, sterilized, aliquoted and stored in the dark at $-20^{\circ} \mathrm{C}$. 3-(4,5-dimethylthiazol-2-yl)-2,5-diphenyltertrazolium bromide tetrazolium (MTT) and Hoechst33342 (HO) were purchased from Sigma Chemical Company (St Louis, MO, USA). Guava Nexin Assay kit (4500-0450) were obtained from Guava technologies Inc (Hayward, CA, USA). 2'7'dichlorodihydrofluorescein-diacetate (DCFH-DA) were supplied by Molecular Probes Inc. (Invitrogen, CA, USA). Antibodies against cleaved poly (ADP-ribose) polymerase (PARP) were obtained from Cell Signaling Technology (Beverly, USA). Caspase- 3 and $\beta$-actin antibody were acquired from Santa Cruz Biotechnology (Santa Cruz, CA). All other reagents were of analytical grade.

\section{Cell culture}

The human acute myeloid leukemia cell line HL-60 was obtained from the Shanghai Research Institute Cell. The cell line was cultured in an RPMI 1640 medium supplemented with $10 \%$ fetal bovine serum, $100 \mathrm{U} / \mathrm{ml}$ penicillin, $100 \mu \mathrm{g} /$ $\mathrm{ml}$ streptomycin, $1 \mathrm{mMl}$-glutamine and $5.95 \mathrm{mg} / \mathrm{ml}$ HEPES. The cells were passaged 1-2 days. Cells were maintained at $37^{\circ} \mathrm{C}$ in a humidified $5 \% \mathrm{CO}_{2}$ atmosphere. Cells in the exponential phase of growth were used in each experiment (cell viability was above $98 \%$ using trypan blue exclusion test).

\section{Ultrasound exposure setup}

The experiment set-up for insonation was similar as previously described (Su et al. 2013). Briefly, the focused ultrasound transducer with a circular ceramic plate of $15 \mathrm{~mm}$ in diameter, manufactured by the Institution of Applied Acoustics, Shaanxi Normal University (Xi'an, China), was submerged in degassed water in the tank facing directly upward. The electrical signal was generated and amplified by a multi-functional generator (AG1020, T\&C Power Conversion, Inc, Rochester, NY, USA) before feeding the transducer. The ultrasound field distribution was recorded by the Ultrasonics C-Scan image System (3560C, Physical acoustics corporation, USA). The central focal spot was shown at about $26 \mathrm{~mm}$ away from the piezoelectric sound source. The produced focus area was about $6-8 \mathrm{~mm}$ in width, and the depth of focus was about $1.6 \mathrm{~cm}$. Ultrasound irradiation was conducted with a frequency of $1.1 \mathrm{MHz}$ in a continuous wave mode for $60 \mathrm{~s}$ duration. $0.5 \mathrm{ml}$ sample contained in a polypropylene test tube was placed into the center of the focal zone for irradiation. Samples were submerged entirely in degassed water and the test tube was rotated at $20 \mathrm{rpm}$ by a micro-motor to improve mixing and to provide a uniform exposure. In 1640-serum free medium, suppose in the free field conditions, we previously evaluated the acoustic intensities in the tube being about $1 \mathrm{~W} / \mathrm{cm}^{2}$ (ISATA, spatial average time average intensity) when the load power by the AG1020 apparatus indicated $3 \mathrm{~W}$, which was used throughout the experiment.

For all experiments, the coupling water was degassed before ultrasound treatment and was maintained at room temperature during irradiation. The temperature inside the test tube was measured before and after ultrasound treatment with a digital thermometer, and no significant variation of temperature was detected $\left( \pm 1^{\circ} \mathrm{C}\right)$. Thus, any bio-effects observed in this study were considered to be non-thermal.

\section{SDT treatment protocols}

HL-60 cells in the exponential phase were collected and divided randomly into four groups: (1) control, (2) PpIX alone, (3) ultrasound alone, and (4) ultrasound plus PpIX. For PpIX and ultrasound plus PpIX groups, the cells were incubated with $0.1 \mu \mathrm{g} / \mathrm{ml}$ PpIX during a $3 \mathrm{~h}$ drug-loading time in the serum-free RPMI 1640 medium, allowing sufficient time for cell uptake of the sensitizer to reach a maximum level. Instead of PpIX, an equivalent quantity of PBS (in $\mathrm{g} / \mathrm{l}: \mathrm{NaCl}$ 
8.0, $\mathrm{KCl} 0.2, \mathrm{Na}_{2} \mathrm{HPO}_{4}$ 1.44, $\mathrm{KH}_{2} \mathrm{PO}_{4}$ 0.24, $\mathrm{pH} 7.2$ ), was used for the control and ultrasound alone groups. The cells in ultrasound and ultrasound plus PpIX groups were exposed to ultrasound at a frequency of $1.1 \mathrm{MHz}$ and an intensity of $1 \mathrm{~W} / \mathrm{cm}^{2}$ for $60 \mathrm{~s}$ duration. After the treatment procedure, cells were re-suspended in fresh medium and cultured for an additional time as specified in the text and then subjected to different analysis.

\section{Cell uptake of PpIX detection by flow cytometry}

HL-60 cells were harvested in an exponential growth phase, washed once with serum-free medium and incubated with various concentrations of PpIX at $37^{\circ} \mathrm{C}$ in a 6-well microplate for different time intervals. Serum-free medium was used to avoid PpIX interact with serum and excrete from the cells.

For determining PpIX content, cells were collected after different incubation time points and immediately detected with flow cytometry Guava easyCyte $8 \mathrm{HT}$ (Millipore, MA, USA). The mean fluorescence intensity of PpIX was recorded at the same measurement conditions.

\section{Cell toxicity assay}

MTT assay relies primarily on the mitochondrial metabolic capacity of viable cells and reflects the intracellular redox state. The MTT assay was used to monitor the cytotoxicity of PpIX-mediated SDT on HL-60 cells. At $4 \mathrm{~h}$ after ultrasound exposure, cells in $100 \mu$ were added to 96 well culture plates, and viability was determined by adding $10 \mu \mathrm{l}$ MTT solution ( $5 \mathrm{mg} / \mathrm{ml}$ in PBS) to each well, and the mixture was incubated for $4 \mathrm{~h}$ at $37^{\circ} \mathrm{C}$ in $\mathrm{CO}_{2}$ incubator. The formazan crystals were dissolved in $100 \mu \mathrm{l} 10 \%$ SDS, $0.01 \mathrm{M} \mathrm{HCl}$ solution, and the absorbance at $570 \mathrm{~nm}$ was recorded using a microplate reader (BIO-TEKELX800, USA) against the reference value at $630 \mathrm{~nm}$. The cell survival of treated samples was then obtained by comparing the results of the incubated but non-exposed control sample.

\section{Analysis of cell apoptosis}

Quantification of cell apoptosis was performed by Guava Nexin assay, which utilizes Annexin V-PE to detect the externalization of phosphatidylserine on the external membrane of apoptotic cells; the membrane-impermeant dye, 7-amino-actinomycin D (7-AAD), is used as an indicator of cell membrane integrity. Briefly, after $2 \mathrm{~h}$ of incubation post SDT, $100 \mu \mathrm{l}$ cells from each sample were suspended in a mixture of $100 \mu \mathrm{l}$ Annexin V-PE and 7-ADD binding buffer and then incubated at room temperature for $20 \mathrm{~min}$. The samples were detected by flow cytometer (Guava easyCyte 8HT, Millipore, Billerica, MA, USA) and analyzed using FCS Express software (De Novo Software, Los Angeles, CA,
USA). Early apoptotic cells were only stained by annexin V-PE, while late apoptotic cells were stained by both annexin $\mathrm{V}-\mathrm{PE}$ and 7-ADD. (Cell apoptosis rate \% = early apoptotic cell rate $\%$ [lower right $\%$ gated] + late apoptotic cell rate $\%$ [upper right $\%$ gated]).

\section{HO staining}

$\mathrm{HO}$ is a fluorescence probe which binds to double-stranded DNA and represents the change of nuclear morphology. HL-60 cells were incubated for $4 \mathrm{~h}$ in a 6-well microplate after the SDT treatment. The stained cells were washed in $1 \mathrm{ml}$ PBS, and both the treated and control cells were stained with $0.1 \mu \mathrm{g} / \mathrm{ml} \mathrm{HO}$ for $30 \mathrm{~min}$ at $37^{\circ} \mathrm{C}$. The stained cells were washed three times in PBS and then observed using a fluorescence microscopy. Excitation wavelength was $364 \mathrm{~nm}$ and emission wavelength was $454 \mathrm{~nm}$. The mean intensity of $\mathrm{HO}$ was analyzed using Image-Pro Plus software.

\section{Western blotting staining}

SDS-PAGE and immunoblotting were performed according to standard procedures. Briefly, cells were lysed by RIPA buffer on ice. The protein samples were separated on a $10 \%$ SDS polyacrylamide gel, and then the gel was transferred to nitrocellulose membranes (Millipore, MA, USA) and blotted with primary antibodies (Caspase- 3 and Cleaved-RARP) overnight at $4^{\circ} \mathrm{C}$. The bound primary antibodies were then tagged with IRDye 680 Conjugated IgG (Li-cor, Biosciences) at room temperature for $1 \mathrm{~h}$. The infrared fluorescence was detected with the Odyssey infrared imaging system (Li-cor Bioscience, Lincoln, NE).

\section{Determination of intracellular ROS}

Intracellular ROS was analyzed using a flow cytometer with DCFH-DA. DCFH-DA, a non fluorescent cell permeant compound, is cleaved by endogenous esterases within the cell and the de-esterified product can be converted into the fluorescent compound 2',7'-dichlorofluorescein (DCF) upon oxidation by intracellular ROS. To estimate intracellular ROS, immediately after treatment, both the control and treated cells were loaded with $100 \mathrm{nM}$ DCFH-DA for 10 min at $37^{\circ} \mathrm{C}$, washed with PBS and immediately analyzed using flow cytometry.

\section{Statistical analysis}

All values were expressed as means \pm SD of at least four independent experiments, the differences among the groups were analyzed by one-way analysis of variance (one-way ANOVA), $p<0.01$ and $p<0.05$ were considered to be significant. 


\section{Results}

\section{Uptakes of PpIX in HL-60 cells}

The intracellular concentration changes of PpIX at different time points after addition to HL-60 cells were evaluated by the mean fluorescence intensity as determined by flow cytometry. As shown in Figure 1, immediately after PpIX administration, the intracellular PpIX increased quickly for the first $1 \mathrm{~h}$, then slightly increased and peaked at $3 \mathrm{~h}$, therein, $0.1 \mu \mathrm{g} / \mathrm{ml}$ and $0.5 \mu \mathrm{g} / \mathrm{ml}$ PpIX display significant increase in PpIX fluorescence in comparison with $0 \mu \mathrm{g} / \mathrm{ml}(p<$ 0.01 ), followed by a slight decrease and almost sustained the same level at $4-5 \mathrm{~h}$ after adding of PpIX. While the intracellular PpIX accumulation curves at different concentrations showed similar trends.

\section{Cytotoxicity of PpIX-SDT on HL-60 cells}

The treated cells were incubated for $4 \mathrm{~h}$ to assess the cytotoxicity of PpIX-mediated SDT on HL-60 cells. The data in Figure 2 revealed that, compared with control, the PpIX alone group and ultrasound alone caused a slight cell damage on HL-60 cell ( $84.8 \%$ and $84.4 \%$ cell survival), whereas the synergistic effect of ultrasound plus PpIX showed significant cell killing, which caused $36.2 \%$ cell viability loss $(p<0.01)$. This combined cytotoxicity of PpIX-SDT was much higher than that of PpIX $(p<0.05)$ or ultrasound alone $(p<0.05)$.

\section{Apoptosis induction in HL-60 cell after SDT}

Flow cytometry with Annexin V-PE and 7-ADD staining was applied to estimate cell apoptosis at $2 \mathrm{~h}$ after SDT treatment. The results in Figure 3 showed that the early and late apoptotic cell populations of HL-60 cells after PpIXmediated SDT significantly increased up to $0.3 \%$ and $39.6 \%$, respectively. In the untreated control group, the early and late apoptotic cell populations were $0.9 \%$ and $2.4 \%$, respectively, which was partly increased to $1.7 \%$ and $13.4 \%$ after $1 \mathrm{~W} / \mathrm{cm}^{2}$ ultrasound treatment; while in PpIX group, these apoptotic cell populations were $1.3 \%$ and $10.5 \%$, respectively. These obtained data suggested that, compared with control, PpIX and ultrasound alone, PpIX-SDT could markedly enhance cell apoptosis in HL-60 cells.

To further verify that PpIX-mediated SDT induced apoptosis of HL-60 cells, HO staining showed that the multiple nucleus were stained a less bright blue and the color was homogeneous in the control groups, and the contrast phase indicated normal cell morphology with intact cell plasma membrane. Cells in PpIX alone group were similar as control cells, cells in ultrasound alone groups showed slight enhancing HO staining and few cells indicated damaged nuclei, and

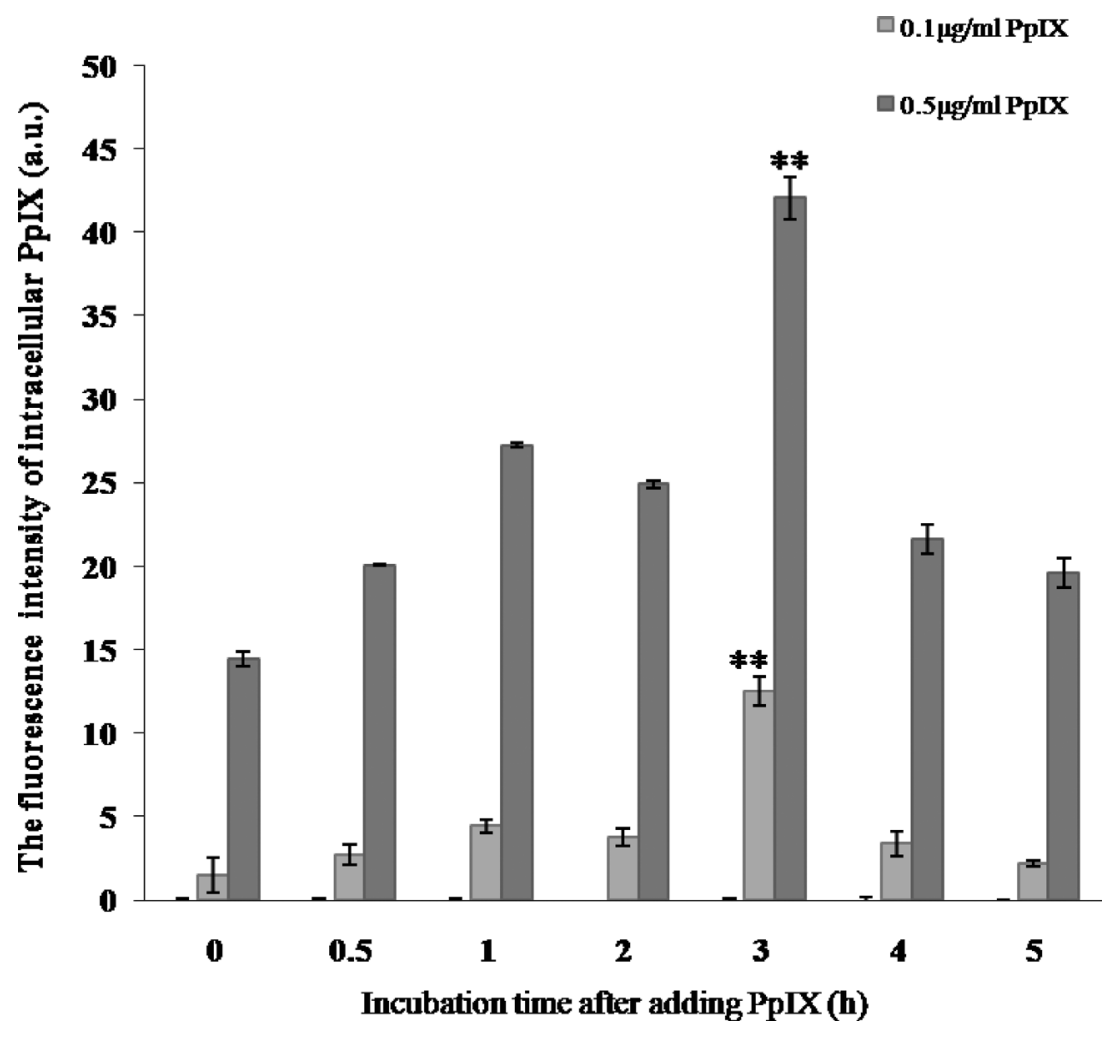

Figure 1. Kinetics of intracellular PpIX level in HL-60 cells after incubation with different concentration of PpIX. Data are presented as mean \pm SD from three independent experiments (every sample has four replicates). ${ }^{* *} p<0.01$ versus untreated controls. 
few cells with plasma membrane blebbing were observed under phase-contrast imaging. After being irradiated by ultrasound with PpIX for $4 \mathrm{~h}$, the blue emission light in apoptotic cells was much bright. Condensation of chromatin and nuclear fragmentations could also be found in many treated cells and some of them formed the structure of apoptotic bodies, which is one of the classic characteristics of apoptotic cells; obviously cell lysis with broken cell membrane were observed under phase-contrast imaging (Fig. 4A,B).

The above-mentioned results imply that the combination of PpIX and ultrasound was more efficient in inducing DNA damage on HL-60 cells than other treatments.

\section{Changes of apoptosis related protein expression}

To further investigate whether the apoptotic effect was involved in PpIX-SDT, we also monitored the key apoptosis related protein changes by using Western blotting. Caspase-3 is a critical executioner of apoptosis (Ghobrial et al. 2005). The applied caspase- 3 antibody detects endogenous levels of full length caspase- $3(35 \mathrm{kDa})$ and the large fragment of caspase-3 resulting form cleavage $(17 \mathrm{kDa})$. As shown in Figure 5, SDT treatment caused increase of typical caspase-3 cleavage at $0.5 \mathrm{~h}$ post treatment, comparing with control, and this cleavage phenomenon almost sustained $6 \mathrm{~h}$ after

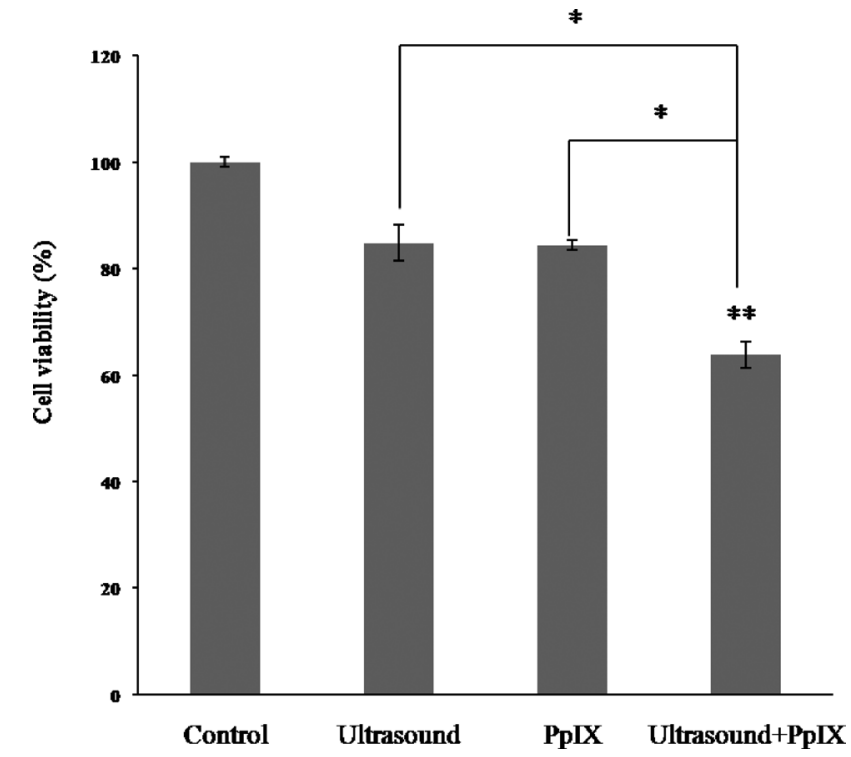

Figure 2. The cytotoxicity of HL-60 cells at $4 \mathrm{~h}$ after PpIX-SDT was assessed by MTT assay. Control, cells without any treatment; Ultrasound, cells were irradiated with $1 \mathrm{~W} / \mathrm{cm}^{2}$ ultrasound alone; PpIX, cells were treated with $0.1 \mu \mathrm{g} / \mathrm{ml}$ PpIX alone; Ultrasound+PpIX, cells were irradiated with $1 \mathrm{~W} / \mathrm{cm}^{2}$ ultrasound in the presence of $0.1 \mu \mathrm{g} / \mathrm{ml} \mathrm{PpIX} .{ }^{*} p<0.05$ versus PpIX and ultrasound; ${ }^{* *} p<0.01$ versus untreated controls.
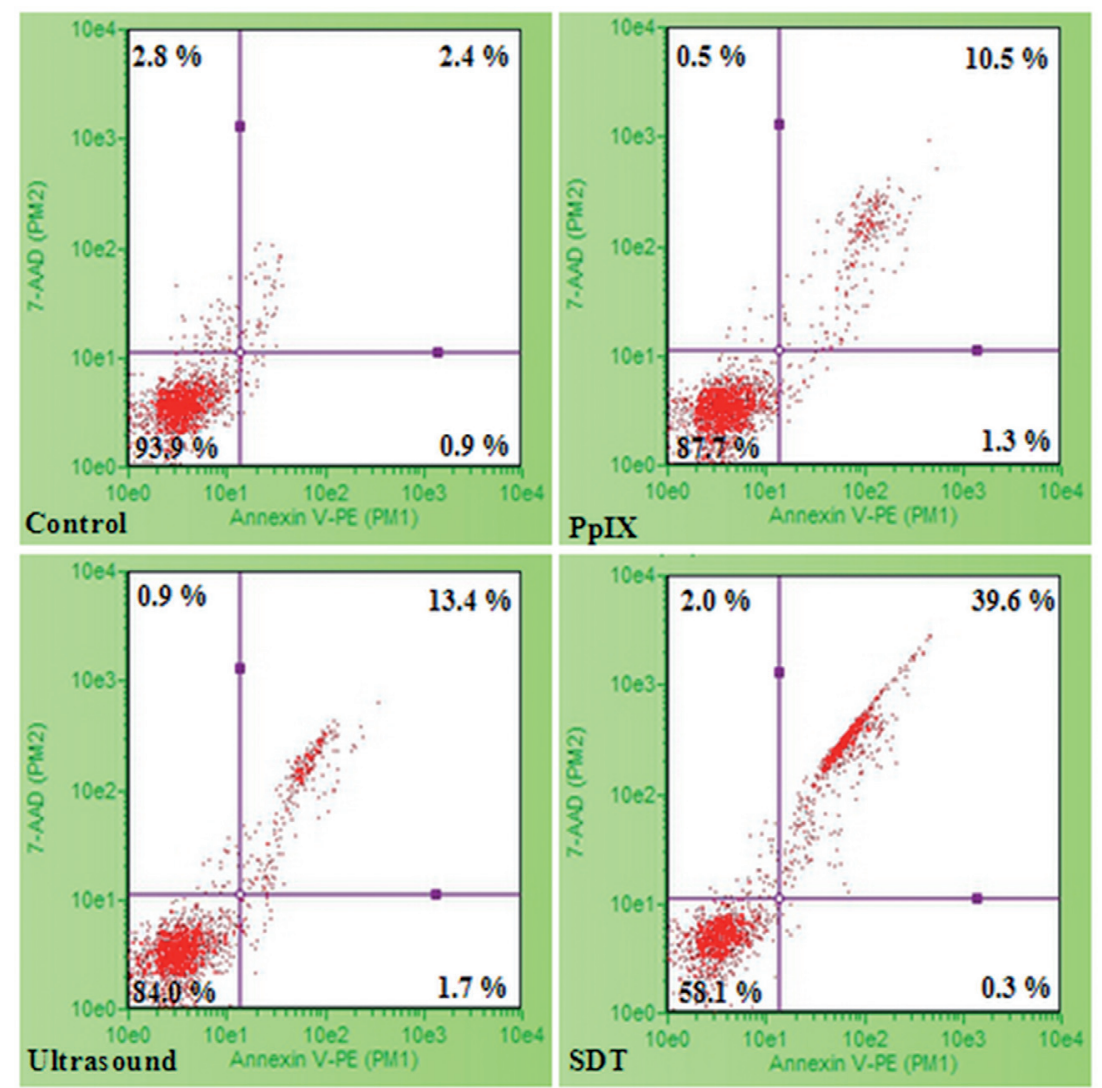

Figure 3. Detection of apoptosis in SDTtreated HL-60 cells using flow cytometry. The cells were double stained with Annexin V-PE and 7-AAD as described in the Materials and Methods after $3 \mathrm{~h}$ incubation following SDT treatment. Control, control group with untreated cell; PpIX, cells were treated with $0.1 \mu \mathrm{g} / \mathrm{ml}$ PpIX alone; Ultrasound, cells were irradiated with $1 \mathrm{~W} / \mathrm{cm}^{2}$ ultrasound alone; SDT, cells were irradiated with $1 \mathrm{~W} / \mathrm{cm}^{2}$ ultrasound in the presence of $0.1 \mu \mathrm{g} / \mathrm{ml}$ PpIX. 
treatment. We know, caspase-3 is either partially or totally responsible for the proteolytic cleavage of many key proteins such as the nuclear enzyme PARP. So, next, we examined PARP cleavage after treatment. The used cleaved PARP (Asp214) antibody detects engogenous levels of the large fragment $(89 \mathrm{kDa})$ of human PARP produced by caspase cleavage. The result showed more obvious cleaved PARP fragment was detected at $2 \mathrm{~h}$ to $6 \mathrm{~h}$ post SDT, which indirectly supported caspase activation and apoptotic response by SDT induction in HL-60 cells (Figure 6).

\section{SDT induces mitochondrial ROS generation}

The intracellular ROS was analyzed using a flow cytometer with DCFH-DA staining immediately after different treatment. As shown in Figure 6, only $4.33 \%$ and $3.83 \%$ of cells in control and PpIX alone group, respectively, showed higher DCF fluorescence, and this percentage of cells slightly increased to $14 \%$ in ultrasound alone group, whereas, about $36.7 \%$ of cells in ultrasound plus PpIX group displayed higher DCF fluorescence. It demonstrated that

A

Control

PpIX

Ultrasound

SDT

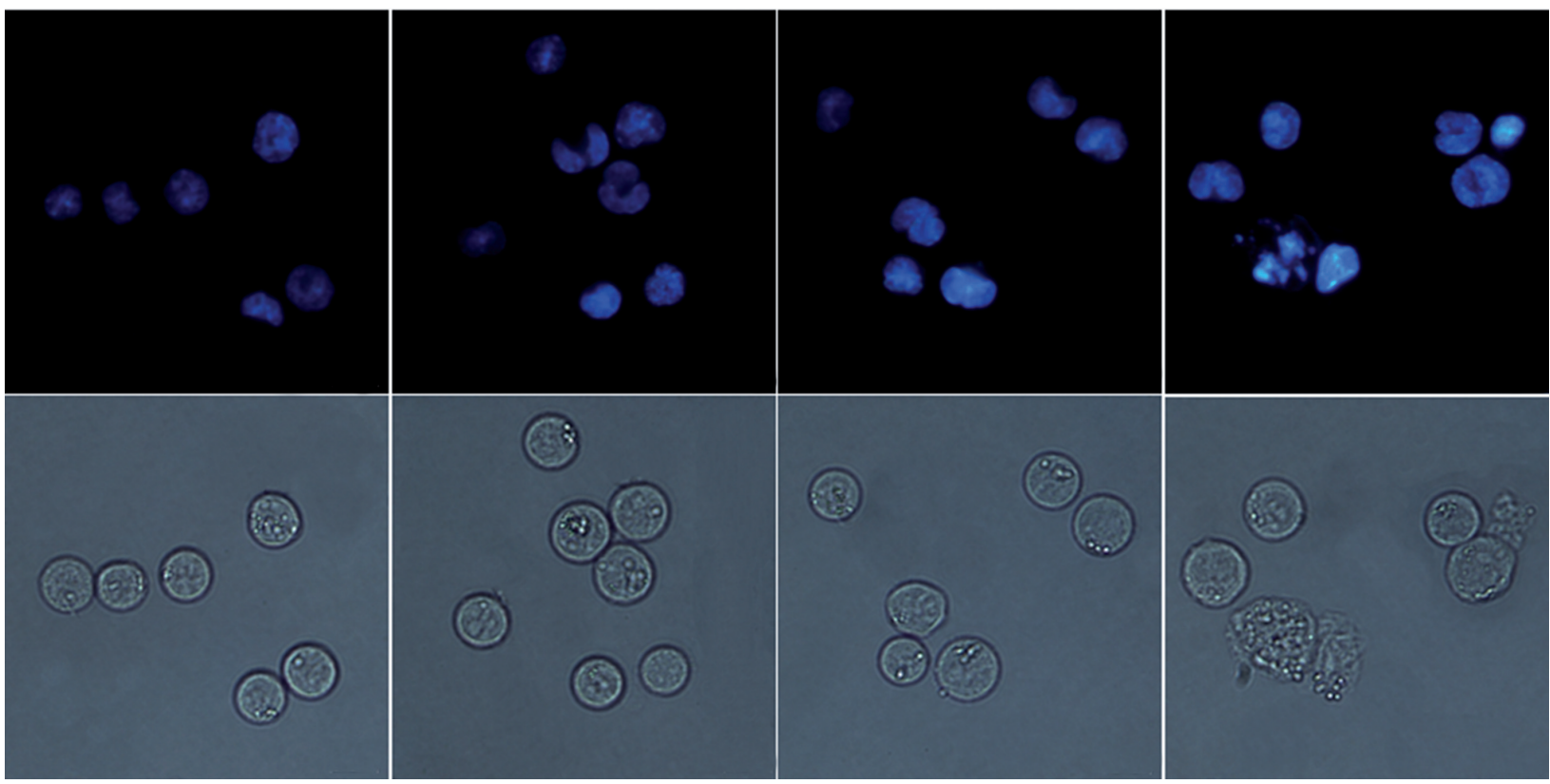

B

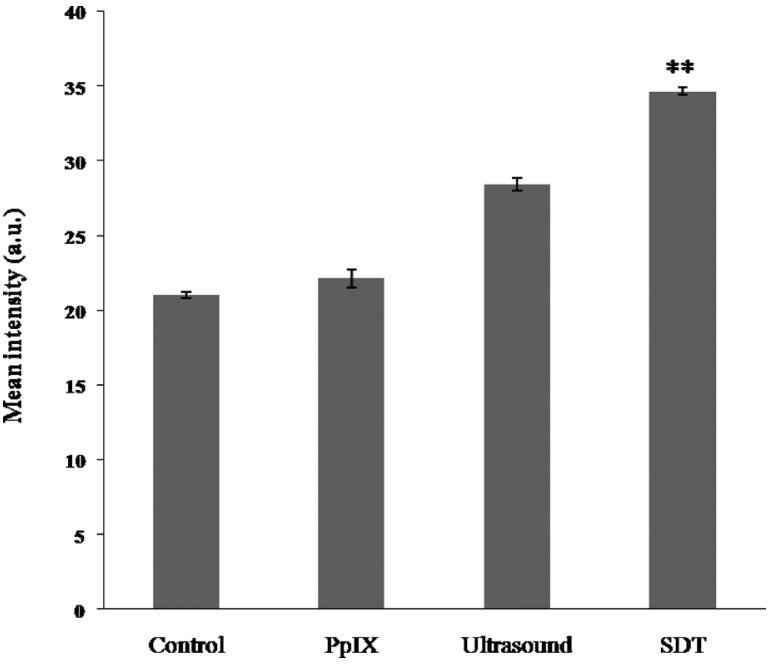

Figure 4. Nuclear HO staining. The stained nuclei were visualized under a fluorescent microscope (A, scale bar: $25 \mu \mathrm{m}$ ). Data expressed as mean $\pm \mathrm{SD}$ of four independent experiments $(\mathbf{B})$. Control, control group with untreated cell; PpIX, cells were treated with $0.1 \mu \mathrm{g} / \mathrm{ml}$ PpIX alone; Ultrasound, cells were irradiated with $1 \mathrm{~W} / \mathrm{cm}^{2}$ ultrasound alone; SDT, cells were irradiated with $1 \mathrm{~W} / \mathrm{cm}^{2}$ ultrasound in the presence of $0.1 \mu \mathrm{g} / \mathrm{ml}$ PpIX. ${ }^{* *} p<0.01$ versus untreated controls. 
PpIX-mediated SDT markedly increased the intracellular ROS level.

\section{Discussion}

It has been proven that ultrasound could enhance cytotoxic therapy in several cell lines (Arthur et al. 2007; Mi et al. 2009; Zhao et al. 2009). In our paper, the MTT assay indicated that the combination of ultrasound and PpIX exerted more significant cytotoxic effect on HL-60 cells than ultrasound alone $(p<0.05)$ or PpIX alone $(p<0.05)$ under the same experimental conditions (Fig. 2), demonstrating that PpIX-mediated SDT was effective on enhancing HL-60 cells toxicity. However, the concrete mechanisms in cell death remain unclear.

Apoptosis is considered to have the most widespread physiological, pathological, and therapeutic roles in response to chemotherapy and physical therapy (Tang et al. 2009), which is an important mode of cell death during sonodynamic therapy (Feril et al. 2005). Lagneaux et al. demonstrated the induction of apoptosis in leukemic cells by a "low-energy" ultrasonic treatment (Lagneaux et al. 2002). In the current paper, to evaluate whether the cytotoxicity of SDT was related to apoptosis, SDT-treated HL-60 cells were stained with Annexin V-PE and 7-AAD. The obtained results showed that at the given experimental conditions, SDT treatment could significantly increase the apoptotic cells $(39.9 \%$ in SDT versus 3.3\% in control, $11.8 \%$ in PpIX, $15.1 \%$ in ultrasound) by flow cytometry with Annexin V-PE/7-AAD double staining (Fig. 3). Also, results of $\mathrm{HO}$ staining showed us the typical apoptotic characteristics in PpIX-SDT, such as nuclear condensation with enhancing HO staining. The altered nuclei morphology was observed in PpIX-SDT-treated cells, and the phase contrast image shows cell lysis and cytoplasmic loss in the combined treatment group (Fig. 4A,B). Additionally, the measurement by Western blotting indicated that after SDT treatment, the apoptotic executioner protein, caspase-3, was obviously cleaved to its active subunit, and the general substrate of caspase-3, PARP, was also cleaved to $89-\mathrm{kDa}$ fragments (Fig. 5). These data implied that apoptosis might

A

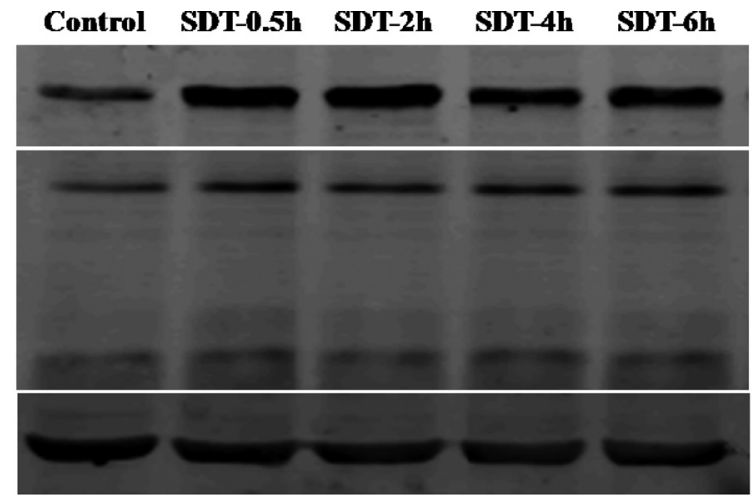

\section{Cleaved PARP}

Procaspase-3

\section{Cleaved caspase-3}

\section{Actin}
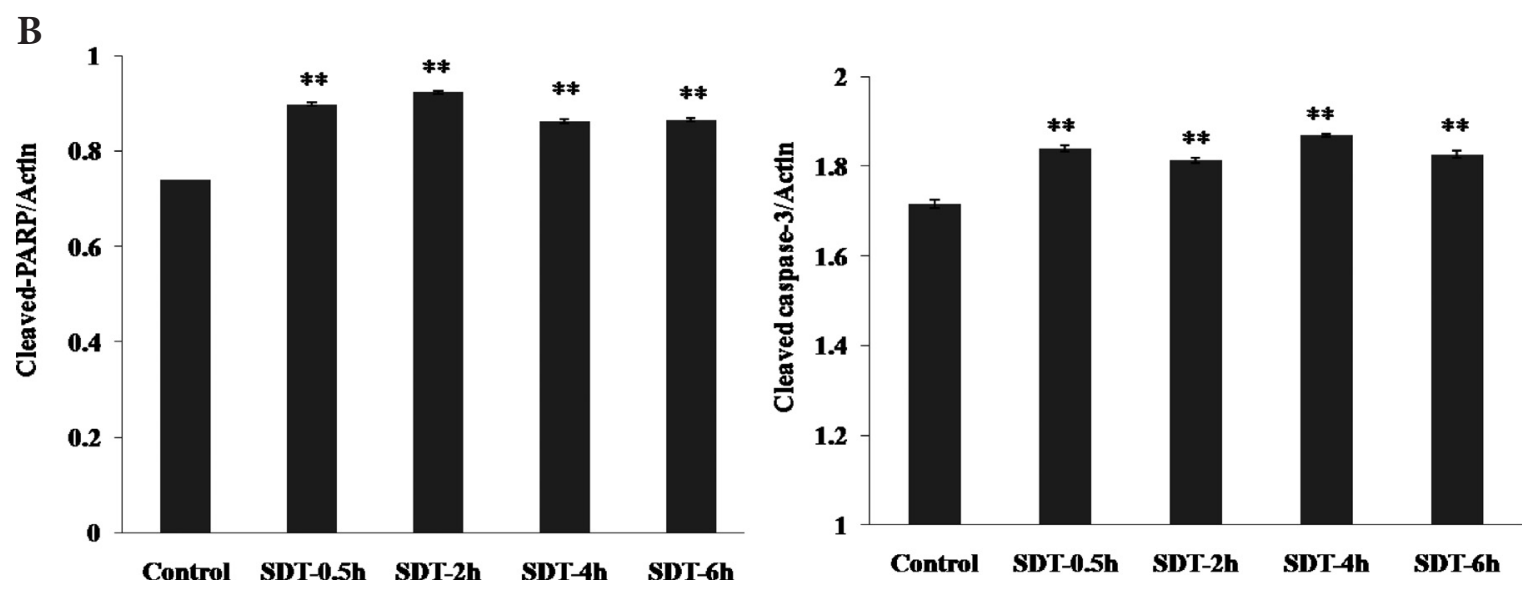

Figure 5. A. Western blotting analysis of cleaved PARP, caspase-3 activation in HL-60 cells after different incubation time following SDT treatment. Actin was used as a loading control. Data expressed as mean \pm SD of four independent assessments (B). Control, cells without any treatment; SDT, cells were irradiated with $1 \mathrm{~W} / \mathrm{cm}^{2}$ ultrasound in the presence of $0.1 \mu \mathrm{g} / \mathrm{ml} \mathrm{PpIX.}{ }^{* *} p<0.01$ versus untreated control group. 
be an important mode of cell death of HL-60 cells after the treatment of PpIX-mediated SDT.

ROS is usually considered as a well-known indicator of apoptosis which has been confirmed to be implicated in numerous therapeutic mechanisms of malignant diseases, including photodynamic therapy, ultrasound therapy, chemotherapy, etc (Gogvadze and Zhivotovsky 2007; Tsuru et al. 2012). Oxidative stress was thought to be one of the major initiators of apoptosis in SDT (Dai et al. 2009; He et al. 2010; Yumita et al. 2010). Previously published studies have shown that low-intensity ultrasound could efficiently activate some sensitizers to produce ROS directly or indi-
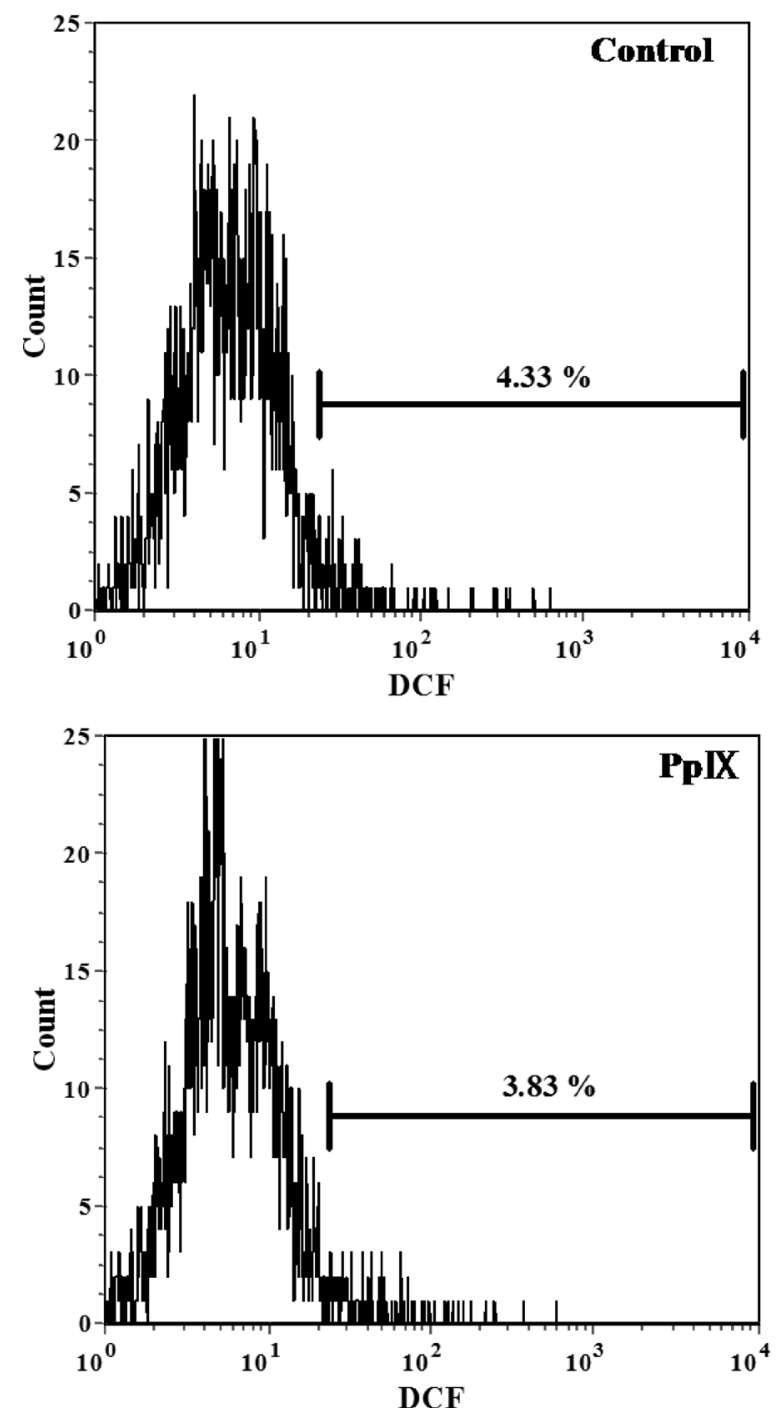

rectly damaging tumor cells (Rosenthal et al. 2004; Hiraoka et al. 2006; Kuroki et al. 2007). Moreover, in 2013, Xu et al. reported that the antitumor effect of SDT on glioma stemlike cells (GSCs) appeared to be primarily dependent on ROS production, and the ROS generation during the synergistic effect of ultrasound and Photofrin decreased cell survival rates and enhanced apoptosis in GSCs (Xu et al. 2013). In our paper, SDT could stimulate the generation of ROS on HL-60 cells obviously (Fig. 6). These data therefore reveal that sonodynamic action of PpIX significantly increased the level of ROS in HL-60 cells, subsequently inducing apoptosis of the HL- 60 cells.
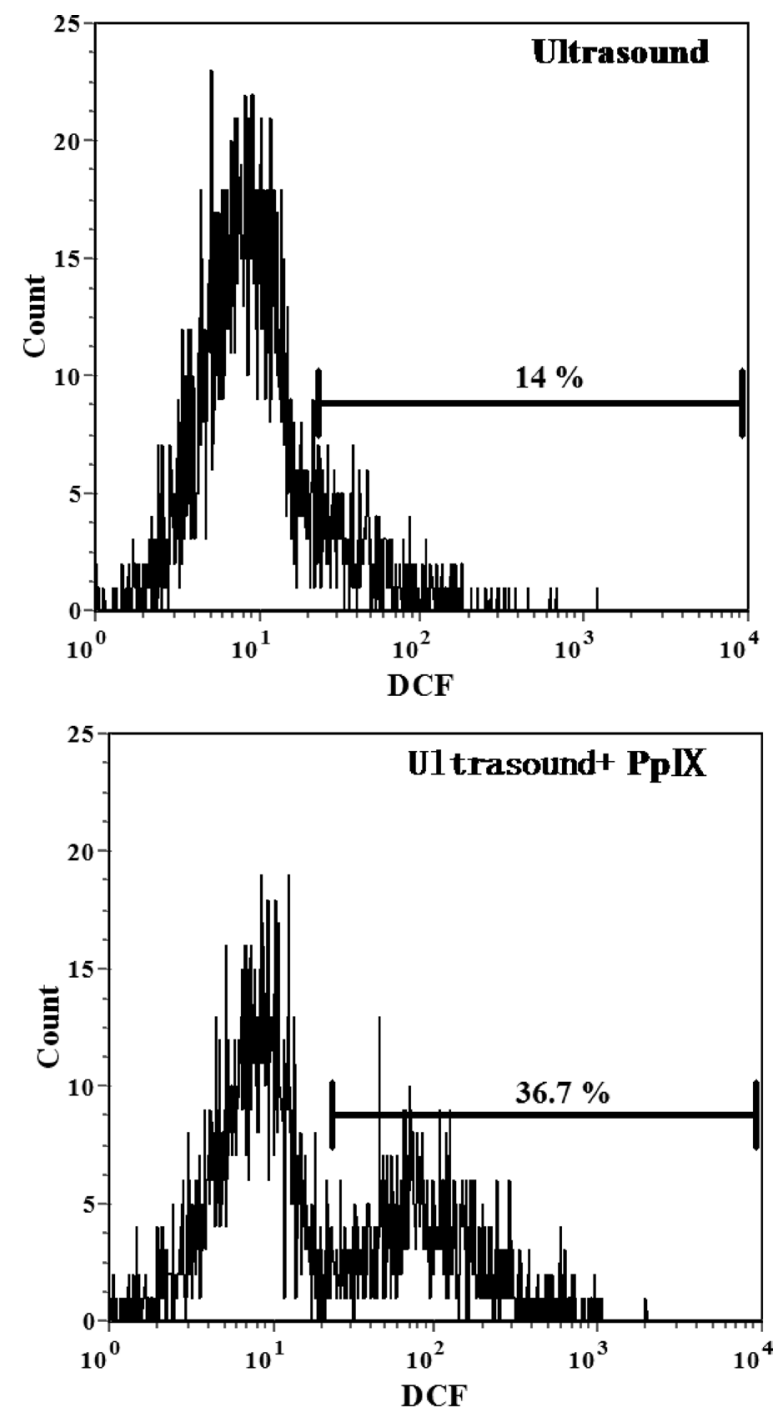

Figure 6. Measurement of intracellular reactive oxygen species (ROS) in HL-60 cells. The cells were labeled with 2',7'-dichlorodihydrofluorescein-diacetate (DCFH-DA), the fluorescence intensity of DCF in the cells was detected by flow cytometry. Control, control group with untreated cell; Ultrasound, cells were irradiated with $1 \mathrm{~W} / \mathrm{cm}^{2}$ ultrasound alone; PpIX, cells with $0.1 \mu \mathrm{g} / \mathrm{ml}$ PpIX alone; Ultrasound+PpIX, cells were irradiated with $1 \mathrm{~W} / \mathrm{cm}^{2}$ ultrasound in the presence of $0.1 \mu \mathrm{g} / \mathrm{ml}$ PpIX; DCF, 2',7'-dichlorofluorescein. The shown data indicate the percentage of cells with higher DCF fluorescence, which represent three independent assessments. 
In the current study, we have demonstrated that SDT was effective on decreasing cell viability, inducing apoptosis and damage in HL-60 cells, ROS was involved in this process. Most importantly, it also indicated that PpIX-mediated SDT could be a potential therapeutic modality for treating leukemia.

Acknowledgements. This work was supported by the National Natural Science Foundation for Young Scholars of China (No. 81000999), the Fundamental Research Funds for the Central Universities (No. GK201102020, GK201404004), the Hong Kong Scholars Program (No. XJ2013034), the Natural Science Foundation of Shaanxi Province, China (No. 2014JQ3092), and the China Postdoctoral Science Foundation (No. 2014M550477).

Conflict of interest. The authors declare that they have no conflict of interest.

\section{References}

Amir H. B., Manijeh-Dizaji M. (2010): Ultrasound dose fractionation in sonodynamic therapy. Ultrasound Med. Biol. 36, 880-887

http://dx.doi.org/10.1016/j.ultrasmedbio.2010.03.010

Arthur C., Flaig T., Su L. J., Denney R., Barnes F., Glodé L. M. (2007): The effect of ultrasonic irradiation on doxorubicininduced cytotoxicity in three human bladder cancer cell lines. Ultrasonics 46, 68-73

http://dx.doi.org/10.1016/j.ultras.2006.10.003

Collins S. J. (1987): The HL-60 promyelocytic leukemia cell line: proliferation, differentiation, and cellular oncogene expression. Blood 70, 1233-1244

Dai S., Hu S., Wu C. (2009): Apoptotic effect of sonodynamic therapy mediated by hematoporphyrin monomethyl ether on C6 glioma cells in vitro. Acta Neurochir. (Wien) 151, 1655-1661 http://dx.doi.org/10.1007/s00701-009-0456-5

Feril L. B. Jr., Kondo T., Cui Z. G., Tabuchi Y., Zhao Q. L., Ando H., Misaki T., Yoshikawa H., Umemura S. (2005): Apoptosis induced by the sonomechanical effects of low intensity pulsed ultrasound in a human leukemia cell line. Cancer Lett. 221, 145-152 http://dx.doi.org/10.1016/j.canlet.2004.08.034

Ghobrial I. M., Witzig T. E., Adjei A. A. (2005): Targeting apoptosis pathways in cancer therapy. CA Cancer J. Clin. 55, 178-194 http://dx.doi.org/10.3322/canjclin.55.3.178

Gogvadze V., Zhivotovsky B. (2007): Alteration of mitochondrial function and cell sensitization to death. J. Bioenerg. Biomembr. 39, 23-30 http://dx.doi.org/10.1007/s10863-006-9054-X

He Y., Xia X., Xu C., Yu H., Bai D., Xiang J., Leung A. W. (2010): 5-Aminolaevulinic acid enhances ultrasound-induced mitochondrial damage in K562 cells. Ultrasonics 50, 777-781 http://dx.doi.org/10.1016/j.ultras.2010.03.004

Hiraoka W., Honda H., Feril Jr. L. B., Kudo N., Kondo T. (2006): Comparison between sonodynamic effect and photodynamic effect with photosensitizers on free radical formation and cell killing. Ultrason. Sonochem. 13, 535-542 http://dx.doi.org/10.1016/j.ultsonch.2005.10.001
Koeffler H. P. (1983): Induction of differentiation of human acute myelogenous leukemia cells: therapeutic implications. Blood 62, 709-721

Kuroki M., Hachimine K., Abe H., Shibaguchi H., Kuroki M., Maekawa S., Yanagisawa J., Kinugasa T., Tanaka T., Yamashita Y. (2007): Sonodynamic therapy of cancer using novel sonosensitizers. Anticancer Res. 27, 3673-3677

Lagneaux L., de Meulenaer E. C., Delforge A., Dejeneffe M., Massy M., Moerman C., Hannecart B., Canivet Y., Lepeltier M. F., Bron D. (2002): Ultrasonic low-energy treatment: a novel approach to induce apoptosis in human leukemic cells. Exp. Hematol. 30, 1293-1301 http://dx.doi.org/10.1016/S0301-472X(02)00920-7

Liu Q., Wang X., Wang P., Qi H., Zhang K., Xiao L. (2006): Sonodynamic effects of protoporphyrin IX disodium salt on isolated sarcoma 180 cells. Ultrasonics 45, 56-60 http://dx.doi.org/10.1016/j.ultras.2006.06.063

Liu Q., Wang X., Wang P., Xiao L., Hao Q. (2007): Comparison between sonodynamic effect with protoporphyrin IX and hematoporphyrin on sarcoma 180. Cancer Chemoter. Pharmacol. 60, 671-680 http://dx.doi.org/10.1007/s00280-006-0413-4

Liu Q., Li X., Xiao L., Wang P., Wang X., Tang W. (2008): Sonodynamically induced antitumor effect of hematoporphyrin on Hepatoma 22. Ultrason. Sonochem. 15, 943-948 http://dx.doi.org/10.1016/j.ultsonch.2008.04.001

Miyoshi N., Misik V., Riesz P. (1997): Sonodynamic toxicity of gallium-porphyrin analogue ATX-70 in human leukemia cells. Radiat. Res. 148, 43-47 http://dx.doi.org/10.2307/3579537

Mi N., Liu Q., Wang X., Zhao X., Tang W., Wang P., Cao B. (2009): Induction of sonodynamic effect with protoporphyrin IX on isolate hepatoma-22 cells. Ultrasound Med. Biol. 35, 680-686 http://dx.doi.org/10.1016/j.ultrasmedbio.2008.07.002

Rosenthal I., Sostaric J. Z., Riesz P. (2004): Sonodynamic therapy - a review of the synergistic effects of drugs and ultrasound. Ultrason. Sonochem. 11, 349-363

http://dx.doi.org/10.1016/j.ultsonch.2004.03.004

Song W., Cui H., Zhang R., Zheng J., Cao W. (2011): Apoptosis of SAS cells induced by sonodynamic therapy using 5-aminolevulinic acid sonosensitizer. Anticancer Res. 31, 39-45

Su X., Wang P., Wang X., Cao B., Li L., Liu Q. (2013): Apoptosis of U937 cells induced by hematoporphyrin monomethyl ether-mediated sonodynamic action. Cancer Biother. Radiopharm. 28, 207-217 http://dx.doi.org/10.1089/cbr.2012.1190

Tang W., Liu Q., Wang X., Wang P., Zhang J., Cao B. (2009): Potential mechanism in sonodynamic therapy and focused ultrasound induced apoptosis in sarcoma 180 cells in vitro. Ultrasonics 49, 786-793

http://dx.doi.org/10.1016/j.ultras.2009.06.002

Tang W., Liu Q., Zhang J., Cao B., Zhao P., Qin X. (2010): In vitro activation of mitochondria-caspase signaling pathway in sonodynamic therapy-induced apoptosis in sarcoma 180 cells. Ultrasonics 50, 567-576 http://dx.doi.org/10.1016/j.ultras.2009.12.001

Tsuru H., Shibaguchi H., Kuroki M., Yamashita Y., Kuroki M. (2012): Tumor growth inhibition by sonodynamic therapy using a novel sonosensitizer. Free Radic. Biol. Med. 53, 464-472 
http://dx.doi.org/10.1016/j.freeradbiomed.2012.04.025

Wang X., Liu Q., Wang P., Zhang K., Tang W., Wang B. (2008): Enhancement of apoptosis by sonodynamic therapy with protoporphyrin IX in isolate sarcoma 180 cells. Cancer Biother. Radiopharm. 23, 238-246

http://dx.doi.org/10.1089/cbr.2007.0436

Wang X., Liu Q., Mi N., Wang P., Tang W., Zhao X., Li X. (2010): Sonodynamically induced apoptosis by protoporphyrin IX on hepatoma-22 cells in vitro. Ultrasound Med. Biol. 36, 667-676 http://dx.doi.org/10.1016/j.ultrasmedbio.2009.09.006

Xu Z. Y., Wang K., Li X. Q., Chen S., Deng J. M., Cheng Y., Wang Z. G. (2013): The ABCG2 transporter is a key molecular determinant of the efficacy of sonodynamic therapy with Photofrin in glioma stem-like cells. Ultrasonics 53, 232-238 http://dx.doi.org/10.1016/j.ultras.2012.06.005

Yumita N., Okudaira K., Momose Y., Umemura S. (2010): Sonodynamically induced apoptosis and active oxygen generation by gallium-porphyrin complex, ATX-70. Cancer Chemother. Pharmacol. 66, 1071-1078 http://dx.doi.org/10.1007/s00280-010-1264-6

Zhao X., Liu Q., Tang W., Wang X., Wang P., Gong L., Wang Y. (2009): Damage effects of protoporphyrin IX-Sonodynamic therapy on the cytoskeletal F-actin of Ehrlich ascites carcinoma cells. Ultrason. Sonochem. 16, 50-56

http://dx.doi.org/10.1016/j.ultsonch.2008.05.005

Received: March 9, 2014

Final version accepted: November 27, 2015

First published online: February 18, 2016 